\section{HETERO-LATERAL ECTOPIA OF THE RIGHT KIDNEY}

BY

\section{R. CAMPBELL BEGG, M.C., M.Sc., M.D., F.R.C.S.Ed., F.A.C.S., F.R.A.C.S. \\ (Johannesburg, South Africa)}

(With Special Plate)

This abnormality is rare but is of clinical importance. The chief features are brought out in the following case.

\section{Case Record}

A young man of 31 , a keen athlete and in perfect health, had been rejected for life insurance five years previously because a trace of albumin had been found in his urine. Examination showed no albumin in the early morning urine and no casts or other pathological findings, microscopical or chemical, at other times. He was normal generally, but palpation of the abdomen was difficult. No kidney could be felt on either side. The blood pressure was $136 / 80$ and the blood urea $42 \mathrm{mg}$. per $100 \mathrm{c.cm}$., both figures high for his age. Urea concentration was 2.18 per cent. in $95 \mathrm{c.cm}$. of urine passed in the second hour; urea clearance with urea (Fowweather's test) 76.9 c.cm. per minute. Blood urea at the end of the second hour was $66 \mathrm{mg}$., again a rather high figure. Intravenous pyelography to exclude polycystic kidneys showed no kidney on the right side and two on the left. He was then examined by cystoscopy and retrograde pyelograms-frontal, lateral, and stereoscopic. These were the findings:

Examination.-Bladder normal; ureteric orifices normal; the right ureter $20 \mathrm{~cm}$. in length, the left $27 \mathrm{~cm}$. The left kidney was normal in size and location, and also in calix distribution and formation. It was incompletely rotated, the pelvis lying in front. The right kidney had passed over to the left side. It lay below and ventral to the left kidney, overlapping its lower third. The pelvis was anterior and small, and was divided immediately into three major calices. The lower calices were normal, the upper large. The papillae of the latter were, however, not flattened. Both kidneys were about equal in size and showed good and equal function in the excretion of per-abrodil. The whole mass extended from the eleventh rib to just above the iliac crest. The left ureter passed forward over the upper part of the lower kidney and then gradually backwards, reaching the bladder on its own side. The right ureter crossed the middle line at the leve of the last lumbar vertebra and entered the bladder at the normal place on the right side (see Plate). When the kidney mass was pressed upwards the relative position of the two pelves was altered, and this, together with the clear overlapping individual shadows, indicated only slight fusion or none between the two kidneys.

There was nothing in these findings to indicate the reason for the albumin, though possibly the postural or vascular conditions which may bring this about in orthostatic albuminuria were imitated by the lower or displaced kidney.

\section{Discussion}

Stewart and Lodge (1923-4) in 6,500 necropsies found fourteen horseshoe, sixteen solitary, and one hetero-lateral ectopic kidney. Morris in 15,908 necropsies found one case of the latter type. If it is permissible to apply these figures to general populations London would have about 14,000 people with horseshoe kidneys, 16,000 with only one, and 1,000 with hetero-lateral ectopia. Owing to the enhanced susceptibility of abnormal kidneys to disease, more of these groups are likely to apply for treatment than similar groups of the ordinary population. Now solitary kidneys may be detected by cystoscopy because of a distorted trigone and only one functioning ureteric

orifice or, if the kidney is double, two orifices on the same side. Horseshoe kidneys may cause embarrassment, but are at least recognized at operation. Hetero-lateral ectopic kidneys, on the other hand, are not readily diagnosed by either of these methods. The ureteric orifices are normal and the passage of ureteral catheters without radiographs does not help. The two kidneys, if not fused, are in close relation within the capsule of Gerota, and even if two ureters are found it may be considered that they belong to a simple double kidney. Unless the surgeon is aware of the condition the whole of the renal substance may be removed, and this has happened on more than one occasion. In no case, then, should pyelograms or radiographs of opaque catheters be omitted.

The cause of hetero-lateral ectopia, especially in the 15 per cent. of cases without fusion, is not clear, but the condition must have its origin when the embryo is little larger than a grain of rice-probably through persistence of the usually transitory direction of the ureteric bud in a dorso-medial direction, which would carry the kidney anlage towards the middle and ultimately to the opposite side. Acute lesions such as rupture place these patients in the greatest danger if pyelography be omitted. Those interested in the subject will be able to follow the literature by referring to recent articles by Carleton (1937) and Patch (1937).

REFERENCES

Carleton, A. (1937). J. Anat., Lond., 71, 292

Patch, F.S (1937) Brit J Urol 9 339

Stewart, M. J., and Lodge, S. D. (1923-4). Brit. J. Surg., 11, 27.

\title{
HYPEROSTOSIS FRONTALIS INTERNA
} (STEWART-MOREL'S SYNDROME)

BY

T. de LEHOCZKY, M.D.

Lecturer in Neurology, University of Budapest

AND

\section{A. ORBÁN, M.D. \\ (With Special Plate)}

During the past few years neurologists have shown an increasing interest in the syndrome often associated with the name of Morel, and each new publication has made some contribution to our knowledge of its aetiology or clinical features. Schiff and Trelles (1931) were inclined to attribute the disorder to trauma ; L. van Bogaert (1930) has brought forth evidence to associate the visual defects with compression of the optic nerve in the bony foramen. There is still, however, a good deal of uncertainty both as to its pathogenesis and to its status as a clinical disorder. At the 1935 Congress of Pathologists in Oslo, Henschen even expressed doubts as to the existence of the syndrome.

\section{Case Report}

Eleven years age the patient, a woman aged 72 , had been ill with a herpes zoster in the left ophthalmic area followed by persistent neuralgic pains. $X$-ray treatment produced a severe dermatitis and ulceration over thc head, which healed with extensive scarring. A year ago alcohol was injected into the lower branch of the left trigeminal nerve. Since that time she has been subjected to numerous forms of treatment -with vaccines, opium, physiotherapy and psychotherapywithout benefit. She had been getting stouter during the last ten to fifteen years, especially over the trunk. No polyuria or polydipsia was present. Sleep was "inverted," the patient being restless during the night and sleepy, tired, and dizzy 
R. CAMPBELL BEGG: HETERO-LATERAL ECTOPIA UF THE RIGHT KIDNEY

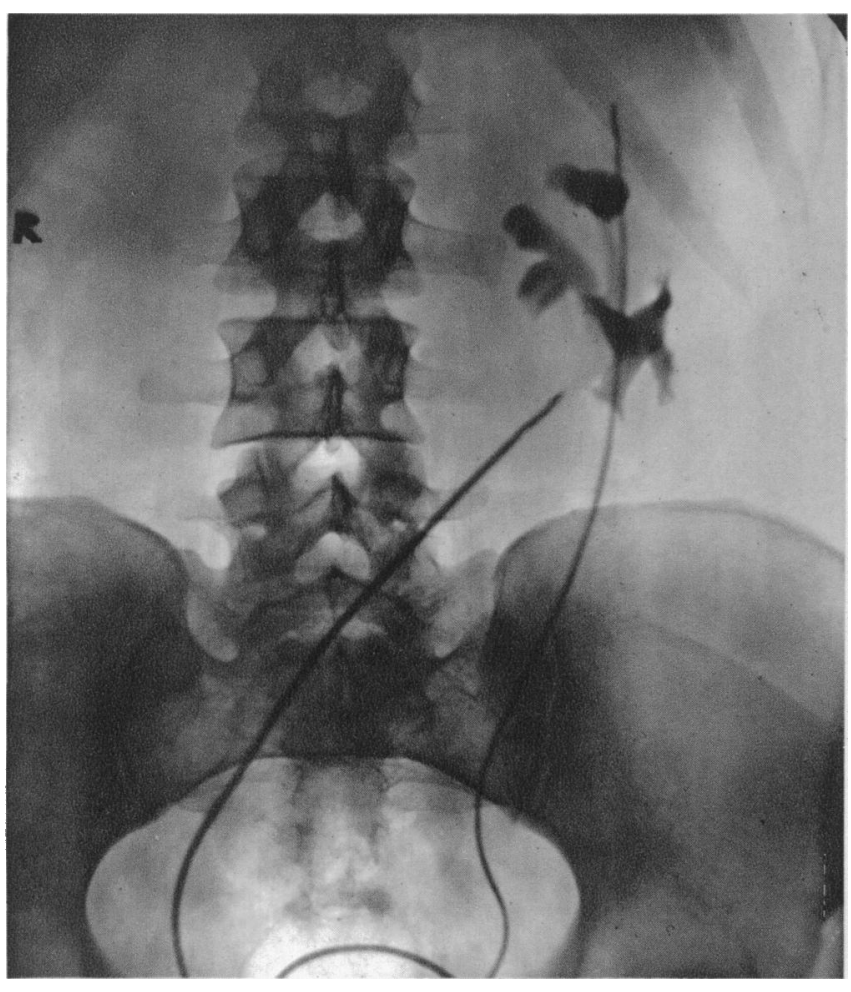

Fia. 1.-Pyelogram of the right or lower kidney. An opaque catheter lies in the left ureter, but the pelvis has not been injected.

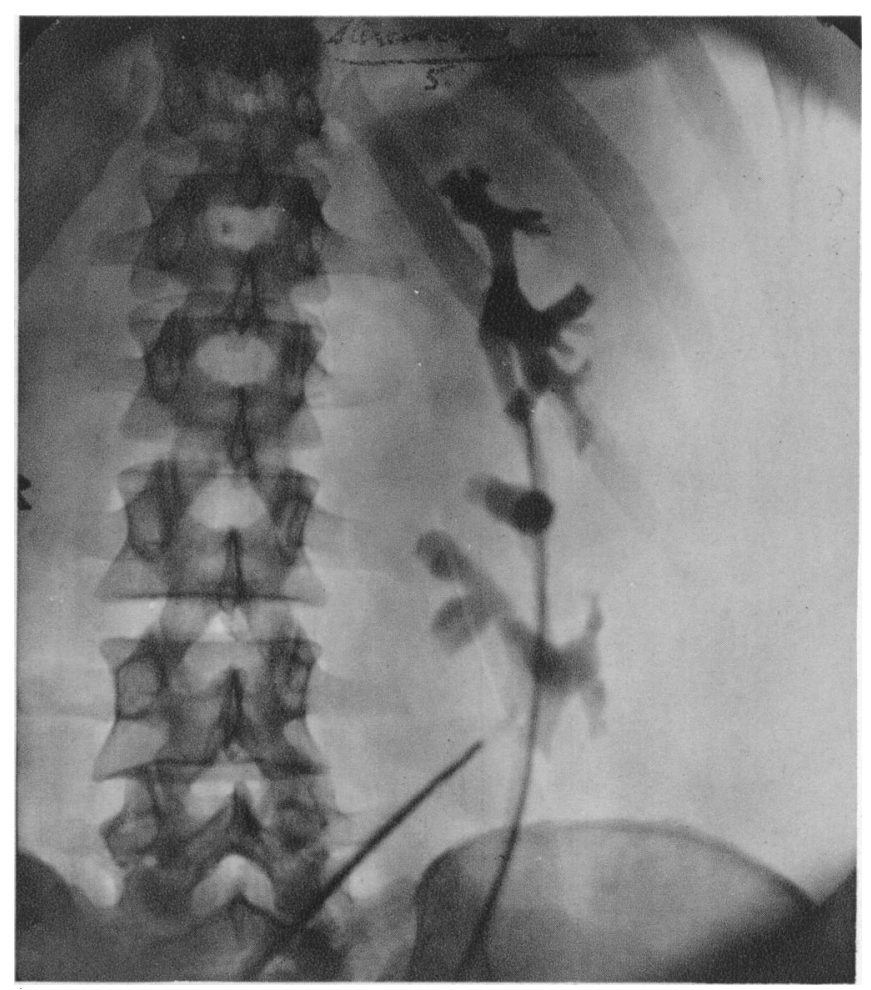

FiG. 2.-Retrograde pyelograms of both kidneys.

T. DE LEHOCZKY AND A. URBÁN : HYPEROSTOSIS FRONTALIS INTERNA 6

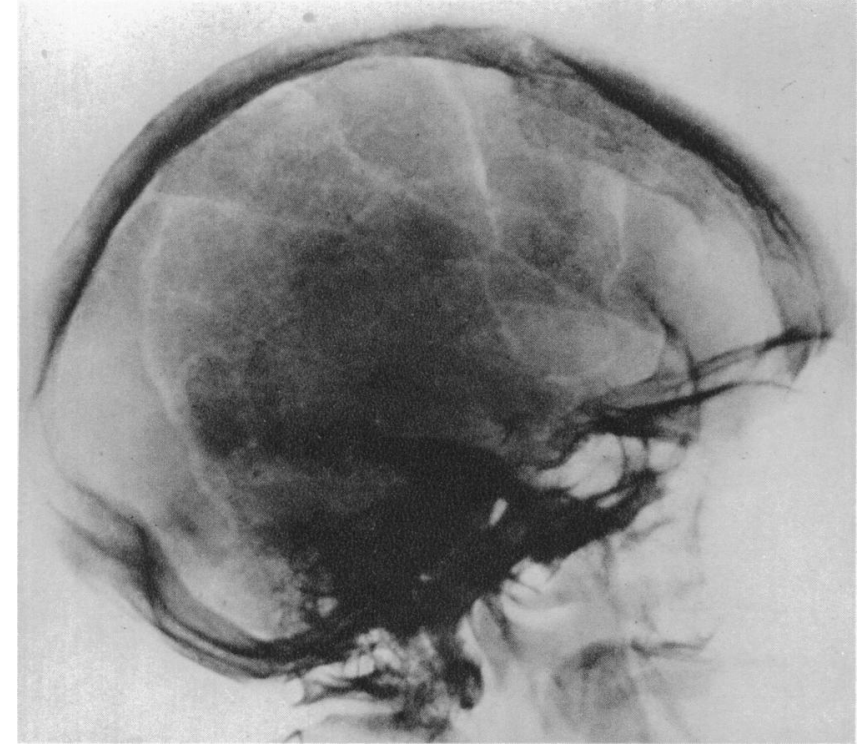

FIG. 1. - Skiagram of skull taken in 1934, showing conspicuous thickening of cranial bones, with senile atrophy of the mandible.

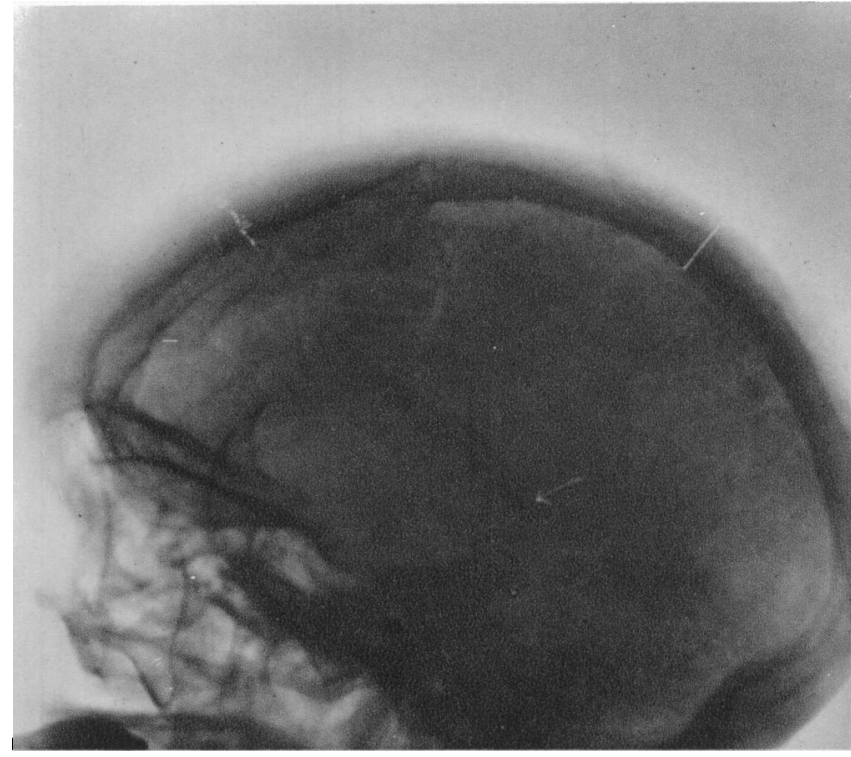

FiG. 2.-Skiagram taken in 1936. Same changes as in Fig. 1, but more pronounced, especially in the frontal bone above the sinus. The frontal portion of the falx cerebri is calcified. 